\title{
El valor de la literatura en la formación de los estudiantes de medicina
}

J osep-E. Baños.

Departamento de Ciencias Experimentales y de la Salud. Facultad de Ciencias de la Salud y de la Vida. Universitat Pompeu Fabra. Barcelona

E ste artíaulo se publica de for ma simultánea en Panace@, B oletín de Medi a na y Traducción 2003; nำ2; http://www.medtrad.org/pana-htm

Cada vez más se acepta el interés de la enseñanza de las humanidades en las facultades de Medicina. Desde que se inició el primer curso de literatura y medicina en la Pennsylvania State University a principio de los años setenta, ha aumentado el número de facultades de Medicina de los Estados Unidos que han incluido un curso de tales características en sus planes de estudio. No obstante, muchos profesores aún dudan del interés de tales actividades y algunos no comprenden su interés para formar estudiantes de medicina. Argumentan que tales cursos no proporcionan ningún conocimiento relevante que no se haya adquirido ya por las materias científicas. Algunas evidencias empíricas, no obstante, desafían tales opiniones. Los cursos de literatura pueden proporcionar información adicional a los estudiantes que puede ser necesaria para comprender mejor algunos aspectos de la práctica médica. Por ejemplo, los aspectos psicológicos y sociológicos de la enfermedad y el papel de los médicos en el tratamiento holístico de ésta pude comprenderse mejor empleando obras literarias que con los libros de texto clásicos de la medicina. Algunas de aquellas son obras maestras de la descripción de las conductas humanas y la enfermedad es una parte frecuente de sus argumentos. En el presente ar tículo, se comenta el interés de la literatura para los estudiantes de Medicina y se presenta una sugerencia de los contenidos que un curso de tales características podría abarcar.

Palabras clave: literatura, humanidades médicas, modelo biopsicosocial, educación médica

\footnotetext{
Correspondencia:

J osep-E. Baños

Departamento de Ciencias Experimentales y de la Salud

Universitat Pompeu Fabra

08003-Barcelona

tel. 34-93-542 2950 • fax 34-93-542 2802

E-mail: J Banos@imim.es
}

Usefulness of literature in the education of medical students

The int erest of teaching humanities in medical schools is increasingly accepted. Since the first course on literature and medicine was started at the Pennsylvania State University in the early seventies, the number of US medical schools offering these courses has increased and now one third of them are including this topic in their curricula. However, many teachers still put in doubt its interest and some of them are unable to understand its usefulness for training medical students. They argue that these courses are not giving any important knowledge that was not already covered by the scientific approach. So me empirical evidences, however, defy such op in ions. Literature courses may give to medical students ad ditio nal informatio $n$ that is needed to understand better so me aspects of medical practice. For instance, p sych ological and so ciological aspects of illness and the role of physicians in the holistic treatment of disease may be better und enstood using literary works rath er than clas sical medical textbooks. Some of the former are masterpieces of human behavior description and sickness is a frequent part of its plot. In the present article, the interest of literature for medical students is discuss ed and the syllabus of a propos al of a Literature and Medicine course is pres ented.

Key words: Literature, medical humanities, biopsychosocial model, medical education.

CONSIDERACIONES PREVIAS (Y, TAL VEZ, LA JUSTIFICACIÓN DE LO QUE SIGUE).

Siempre que hablo del interés dela literatura, y en general las humanidades, para la educación de los estudiantes de medicina, se plantea en los contertulios la duda desi realmente sirven para algo. Sus pre guntas son razonables: ¿qué conoci mientos, actitudes 
o habilidades aportarán a los futuros médicos que no puedan obtener con las materias tradicionales que cursan en su licendiatura? ¿Por qué pasar horas leyendo sobre algo que nunca existió en lugar de estudiar los hechos reales presentes en las ciencias médicas científicas? No siemprees fácil convencer los, pero a menudo empleo el nada original argumento de alguna obra literaria. En un magnífico artículo sobre El amor en los ti empos del cólera de Gabriel Garáa Márquez, J ones ${ }^{1}$, una de las primeras defensoras de la necesidad de compaginar literatura y medicina en la formación de los médicos, daba su respuesta a las pr eguntas planteadas unas líneas antes: las novelas permiten conocer hechos y situadiones que difíalmente se encuentran en los libros de texto tradicional es de medicina. ${ }^{2}$ Por ejemplo, la dbra citada ofrece un espléndido fresco sobre el envejecimiento, las limitaciones físicas que conlleva y la manera de sobrellevarlas. Estos conocimientos son, en mi opinión, de notable impor tancia para la mayoría de los estudiantes que en sus años universitarios apenas pueden imaginar lo que puede suponer la vejez para muchos de sus futuros pacientes. Conocerlos puede evitarles errores (a ellos) y sufrimientos (a sus pacientes) innecesarios.

¿Por qué medicina y literatura? se preguntaban también en el primer número de Literature and Medicine', hace ya veinteaños. En el tiempo transcurrido desdeentonces se han dado muchas respuestas, aunque las que han tenido más aceptación son las llamadas explicaciones estéticas y éticas ${ }^{3}$ Las primeras defienden que enseñar a los estudiantes a leer, en $\mathrm{d}$ sentido más amplio, ayuda a formar los médicamente. Las segundas señalan que la única función de la literatura en las facultades de M edicina sería enseñar reflexión ética. En mi opinión el asunto es más fádil de comprender si huimos de anál isis académicos. La literatura, como la medicina, tiene la condición humana, con todas sus características de singularidad y de misterio, como uno de sus objetivos prindpales. Por esta razón, el estudio de la ficción, la pœsía o las obras dramáticas pueden permitir a los estudiantes acceder a las experiencias de los pacientes, de la familia y aun de propio médico. Asimismo, les pone en contacto con las consecuencias de la enfermedad, las incapacidades derivadas de ésta, la atención a los enfermos y a los moribundos, y la inevitabilidad del envejecimiento y de la muerte.

La relación entre literatura y los médicos tiene una larga tradición que sól o comentaré brevemente. Es tradicional citar a Antón Pávlovich Chéjov (18601904), que simultaneó ambos oficios durante toda su vida y que llegó a afirmar que la medicina era su esposa y la literatura su amante ${ }^{4}$. Por supuesto, Chéjov no era una excepción y en la nómina de médicos-escritores (o escritores médicos) también reconocemos a François Rabelais (circa 1494-1553), Arthur Conan Doyle (1859-1930), William Somerset Maugham (1874-1965) o William Carlos Williams (1883-1963), entre muchos otros. Entre los nuestros, podemos recordar a Diego de Torres Villaroel (16931770), Andrés Bello (1781-1865), J osé Rizal (18611896), Gregorio Marañón (1887-1960) o Pedro Laín Entralgo (1908-2001). En un ensayo reciente, Navarro ${ }^{5}$ ha analizado las múltiples razones que han convertido a los médicos en escritores en todas las épocas y países. Entre todas las que esgrime para justificar esta frecuente relación, la que más me convence es el argumento de que el contacto diario de los médicos con los seres humanos les incita a la escritura. En esta analogía, no es iluso creer que las obras literarias, que casi siempre les tienen como protagonistas, acaben interesando a los médicos. Aceptando esta premisa, es razonable pensar que su análisis puede enriquecer notablemente la educación de los estudiantes de medicina.

En realidad, la idea de los cursos de literatura y medicina para estudiantes de medicina no es nueva. E $n$ los Estados Unidos el primer programa de literatura en una facultad de Medicina se inició en la Pennsylvania State University Coll ege en Hershey cuando J oanne Trautmann (Banks) empezó a impartirloen $1972^{6}$. Desde entonces, esta materia está presente en aproximadamente un tercio de las facultades de Medicina de los Estados Unidos con el objetivo de enriquecer los curriculums médicos, centrados general menteen la transmisión neutra de los hechos científicos. Esta situación refleja el interés de la enseñanza de las humanidades en las facultades de Medicina, aunque no todos los profesores tienen una opinión unánime a este respecto ${ }^{7}$. Pero el avance ha sido notable y, de una forma $u$ otra, se han dado cursos de humanidades en las dos últimas décadas en uni versidades de todo el mundo, tanto a estudiantes de medicina como a licendiados ${ }^{6}$.

\section{EL PO RQUÉ DE LA LITERA TURA EN LA ENSEÑANZA DE LA MEDICINA}

Pocos negarán que los escritos médicos son, en general, prolijos por sistemáticos, aburridos por reiterativos y desincentivadores por abstractos. Quizá estamos tan acostumbrados a la lectura de las obras médicas que no nos importuna su aridez. Las obras 
literarias son otra cosa. Veamos, por ejemplo, cómo el emperador describe su propia enfermedad en la obra Memorias de Adriano de Marguerite Yourcenar:

"He ido esta mañana a ver a mi médico Hermógenes, que acaba de regresar a la Villa después de un largo viaje por Asia. El examen debí a hacerse en ayu nas. Habíamos convenido encontrarnos en las prime rashoras del día. M etendí sobreun l echoluego dedes pgarmede manto yla túnica. Teevito detalles que te resultarían tan desagradables como a mí mismo, y la descripción de cuerpo de un hombrequeenvejece y se prepara a morir de una hidropesía de corazón. Digamos solamentequetosí, respiréy contuved alien to conforme a Ias indicadiones de Hermógenes, alar mado a pesar suyo por e rápido progreso de la enfer medad, y pronto a descargar e peso de la cul pa en el joven Id las, que me atendió durante su ausencia. Es difícil seguir si endo emperador ante un médico, y tam bi én es difícil guar dar la calidad dehombre El ojo de Hermógenes sól o véa en mi un saco de humores, una triste amalgama de linfa y de sangre Esta mañana pensé por primera vez que mi cuerpo, ese compañero fiel, ese amigo más seguro y mejor conocido que mi alma, no es más que un monstruo solapado que aca bará por devorar a su amo. Haya paz... Amo mi cuer po: me ha servido bi en, y de todos modos no le escati mo los auidados necesarios. Pero ya no cuento, como Hermógenes finge contar, con l as virtudes maravillo sas de las plantas y e dosaje exacto del as sales mine rales que ha ido a buscar a Ori ente Este hombre, tan sutil sin embargo, abundó en vagas fórmulas de alien to, demasi ado triviales para engañar a nadie Sabe muy bien cuánto detesto esta d ase de impostura, pero no en vano ha ejerci do la medicina durante más de treinta años. Perdono a estebuen servidor su esfuerzo por di simularme la muerte Hermógenes es sabio, y ti ene tambi én la sabi duría dela prudencia: su probi dad excede con mucho a la de un vulgar médico de palacio.Tendréla suertedeser e mejor atendido de los enfermos. Pero nada puede ya exceder de los límites prescritos; mis pi ernas hinchadas ya no me sostienen durante las largas ceremonias romanas; me sofoco; y tengo sesenta años"

Es difícil describir de forma tan diáfana la evolución de una enfermedad crónica, la consideración del paciente respecto a su progresión o las sutilezas de la relación médico-enfermo. Compárese la descripción de los edemas de la obra anterior con un fragmento escogido al azar de una obra médica9:

"EI vaciado ventricular incompleto y la relajación ventricular inadecuada producen una elevación de la presión diastólica ventricular. Si el deterioro de la función cardíaca afecta al ventrículo derecho, las presiones en las venas y capilares sistémi cos puede elevarse, aumentando así la trasudación de líquido hacia el espacio intersticial y favoreciendo la apari ción de edema periférico. La elevada presión venosa sistémica se transmite al conducto torácico con la consecuente reducción de drenaje linfático, que aumenta todavía más la acumulación de edema."

No estoy, por supuesto, denostando de las obras de medicina empleadas para la formación de los estudiantes y la actualización de los médicos en ejercicio. Pero lo cier to es que, quizá por su propio carácter, no es frecuente que en los grandes tratados se encuentren referencias a algunos aspectos de la enfermedad queson importantes para quel os estudiantes puedan comprender lo que significa de una forma holística. En otras palabras, la descripción de la producción de los edemas en el texto citado es una transcripción de un mero proceso biofísico, y necesaria para comprender cómo se producen aquellos. Durante mi vida de estudiante no recuerdo haber leído en ninguna parte (ni que nadie me explicara) cómo los edemas, y por extensión la insuficiencia cardíaca, pueden llegar a alterar la vida de quién los sufre. Para mí es evidente que las lecturas del texto médico y de la obra de Yourcenar son complementarias, pues si la primera per mite conocer el hecho biológico, la segunda aporta la comprensión de las consecuencias personales de esa alteración de origen bi ofísico.

Otro ejemplo, más acorde con la materia que imparto periódicamente a mis estudiantes, se refiere al problema de la infrautilización de los opioides por el miedo a la farmacodependencia (la famosa opiofo bia) y al sufrimiento innecesario que tal situación genera. Se hace difícil en ocasiones que los estudiantes comprendan esta situación cuando son confrontados con las evidencias de la seguridad del uso detales analgésicos respecto al riesgo de inducir adicción cuando se emplean correctamente. En una de las obras esenciales de la farmacología puede leerse ${ }^{10}$ :

"Algunos díni cos, a causa de su preocupación exce siva por la posibilidad deinduci $r$ adica ón, tienden a prescribir dosis iniciales de opioides que son dema siado pequeñas o que se admini stran con muy poca frecuencia para ali viar el dolor, y a continuaci ón reac cionan a las md estias sostenidas por el pacientecon una preocupación induso más exagerada sobre la dependencia del fármaco, a pesar de la gran probabi lidad de que la solicitud de más cantidad de medica mento sea sólo la consecuencia esperada de la dosifi cación insuficiente prescrita desdeun principi o." 
Indiscutiblemente, esta explicación es absolutamente correcta, pero no permite conocer las consecuencias que puede suponer tal conducta para los pacientes que precisan analgésicos potentes, ni de las razones por los quelos médicos la adoptan. De nuevo, la literatura nos ofrece una visión más vívida y emocional de lo que puede ocurrir en situaciones más o menos reales. Veamos tres ejemplos, el primer o de la emotiva obra Una muerte muy dulce ${ }^{11}$, escrita por Simone de Beauvoir en 1964 tras la muerte de su madre a consecuencia de un cáncer intestinal:

"Pasé la noche a su lado. Temía a las pesadillas tanto como al dolor. Cuando llegó el doctor $\mathrm{N}$ le pidió: "Que me pongan tantas inyecciones como sea necesario", imitando el gesto de la enfermera que clava la aguja: "iAh, ah! ¡se va a convertir en una auténtica drogadicta le dijo el doctor en tono de broma: "Le podré conseguir morfina a precios muy ventajosos." Su rostro se mudó y me espetó con voz dura: "Hay dos puntos sobre los cuales un médico que se respete no transige: la droga y el aborto".

El segundo ejempl o vi ene de la obra La enferme dad deSachs ${ }^{12}$, escrita por el médico francés $M$ artin Winckler, y recomendable por muchas otras razones:

"Sé que a veces la gente llama al médico porque tienen miedo de queles duela, antes de queles dé los jóvenes de hoy en día son tan delicados, tan insegu ros, tan preocupados por la mínima cosa. Pero por cuatro personas que tienen más miedo que dolor y que en cuanto llega el médico, ya se encuentran mejor, hay una quinta que se retuerce de dol or, que no sabe dónde meterse, en qué posición, porque les tortura, en el vientre, en el pecho o en otro sitio, y es insoportable Ésos, si tienen quevérsel as con al gunos de tus compañeros, lo llevan claro si quieren verse aliviados (cuántas veces heoído a gente decir queles habían dejado sufrir, a ellos, a su padre o su herma no, y los médicos decían que no podían hacer nada, que sobre todo, no había que enmascarar los sínto mas, que el dolor es útil, permite que el médico sepa lo que está pasando, parece que les molesta ver a la gente encontrarse mejor), pero si tienen la suerte de dar contigo, pasarán el resto de la noche tranquilos. A ti, no te mol esta que los pacientes no sufran".

El tercer ejemplo proviene de la novela de I sabel Allende, Retrato en sepia ${ }^{12}$, en el que se describe el alivio del dolor que la abuela de la protagonista sufre en los últimos días de su vida:

"En esos días tuve muchas ocasiones de ver a Gengis Khan, quien controlaba el estado de la paciente y resultó, como era de esperar, más asequi ble que el cél ebre doctor Suffolk o las severas matro - nas del establecimiento. Contestaba a las inquietu des de mi abuela sin vagas respuestas de consuelo, sino con explicaciones racionales, y era el único que procuraba aliviar su aflicción, los demás se intere saban en el estado de la herida y la fiebre, pero igno raban los quejidos de la paciente. ¿Pretendía acaso que no le doliera? Más bien debía callarse la boca y agradecer que le hubieran salvado la vida, en cam bi o e joven doctor chileno no ahorraba morfina, por que creía que el sufrimiento sostenido acaba con la resistencia física y moral del enfermo, retardando o impidiendo la sanación, como le aclaró a Williams."

De nuevo, no hay duda que los estudiantes deben aprender la farmacología de los analgésicos opioides para conocer los riesgos asociados a su uso, perotambién es indiscutible que los textos citados les permiten adquirir una información directa de lo que sucedecuandotales fár macos no se utilizan de forma óptima para aliviar el sufrimiento. Los tres ejemplos son muestras de cómo las obras literarias pueden ayudar a comprender mejor la profesión médica a aquellos que se acercan a las facultades de Medicina.

\section{DE MI INTERÉS POR LA LITERATURA EN LOS ESTUDIOS MÉDICOS}

En agosto de 1999 me encontraba en uno de esos congresos mundiales que reúnen durante unos días a miles de especialistas en lugares generalmente más atractivos para la visita turística que para la sesuda reflexión científica. En mi vagar por las llamadas exposiciones comerciales, me acerqué a la de una librería local. Curioseando entre los libros expuestos, me llamó la atención uno de ellos por su curioso título: Narrativebased medidine ${ }^{14}$. ¡Caramba! - pensé -, en estos tiempos de la medicina basada en la evidencia (o mejor, medicina factual), ¿qué debe ser esto de la medicina basada en narraciones? Lo tomé del estante para hojearlo interesado. Lo primero que me Ilamó la atención fueron los editores, nadie sospechoso de publicar banalidades. La lista de autores era también sugestiva: clínicos de distinto origen junto a profesionales de las humanidades. Los títulos de los capítulos tampoco tenían desperdicio. En fin, la lectura rápida de algunos párrafos me convenció. Me lo quedé. Fue como una conversión paulina, aunque había sucedido en Viena y no camino de Damasco.

Aquí empezó todo. En plena fiebre médico-literaria, una de las revistas más prestigiosas en el ámbito de la medicina dínica inició una serie de artículos sobre este tema ${ }^{15-17}$ y descubrí que poco antes había publica- 
do un suplemento dedicado a literatura, medicina y envejecimiento ${ }^{18}$. A fin de observar la bondad de sistema, me desplacéhacealgunos meses ala Penn State University Medical College en Hershey (Pensylvannia) a fin de observar in situ la organizadión de la que constituyó la primera facultad que integró la literatura en particular, y las humanidades en general, en su plan de estudios de Medicina. Ann Hunsacker Hawkins es quien dirige el programa de literatura y fue un placer asistir a sus seminarios para estudiantes de M edicina y ler los contenidos de Wil d Onions, la revista de humanidades médicas que publica su departamento y en el que pueden leerselas contribuciones literarias de los estudiantes y miembros del Medical Coll ege Para mí fueel espaldarazo definitivo para considerar que la literatura podía ser un tema importanteen las facultades de M edicina. Delo que vi allí, de las lecturas y de las reflexiones nace la propuesta que detallo en la sección siguiente

\section{UNA PROPUESTA DE CURSO DE LITER ATURA Y MEDICINA PARA ESTUDIANTES DE MEDICINA}

En cualquier aurso debe definirse los objeivos educativos para proceder de manera racional a su planificación. Algunos autores los han establecido para los dedicados a literatura y medicina y el propuesto acepta, con al gunos matices, los enunciados en la Tabla1. El dbjetivo principal sería permitir la discusión de algunos aspectos de la actividad médica que consider o primordiales para ejercer la profesión correctamente. Para alcanzarlo, se pretende que los estudiantes de los años preclínicos reconozcan pronto los elementos psicológicos y sociológicos asociados a la enfermedad, en el convencimiento que con ello se podría conseguir una actitud más positiva y, más adelante, una práctica más humana de la medicina. Se desea, en fin, que los estudiantes consi deren a los pacientes como personas que enferman y no como meros casos. En esta filosofía también es importante induir sesiones sobre la ética de la investigación médica y las características de la profesión médica, aspectos ambos esenciales para el ejercicio adecuado de la profesión en el sigloque se ha iniciado.

El método docente consistiría en el trabajo con un grupo reducido de alumnos (no más de 15). Cada estudiante debería leer una obra completa de las escogidas en el curso, y redactar un estudio que pre sentará al resto de los miembros del grupo. Este estudio debería recoger los datos biográficos del personaje, analizar la obra en su contexto histórico, identificar los elementos de interés médico y describir sus características literarias básicas. EI resto de miembros del grupo deberían haber leído previamente un fragmento recomendado de la obra en cuestión, lo que les permitiría conocerla y comentar los aspectos más relevantes en la sesión de grupo. Los grandes temas que se desean tratar, así como las obras que podrían emplearse, se describen a continuación.

Las repercusiones psicológicas de la enfer medad. En esta sección se desea que los estudiantes comprendan cómo la enfermedad afecta a la vida de aquellos que la sufren, especialmente cuando es irreversible o mortal. Las obras escogidas son la ya citada Una muerte muy dulce (1964) de Simone de Beauvoir, La muerte de Ivan IIlych (1879) de Leon Tolstoi, El Pabelón número 6 (1892) de Antón Chejov y Pabelón de cáncer (1971) de Aleksandr Solzhenitsyn.

La enfermedad en primera persona. Existen numerosas obras en las que los autores narran las vivencias generadas por la enfermedad que sufren o han sufrido. Esta amplia disponibilidad permite escoger algunas de ellas para ofrecer una visión de primera mano de cómo la viven los afectados, y su

Tabla 1. Ejemplos de objetivos generales de un curso de literatura y medicina para estudiantes de medicina (modificado de Squier ${ }^{19}$ )

- Profundizar en el conocimiento de las perspectivas de los pacientes y de los médicos frente a la enfermedad como para parte de la relación médico-paciente.

- Preparar y motivar en la adquisición de las técnicas de entrevista clínica.

- Preparar para los años clínicos mediante una mejora del conocimiento de los temas psicosociales y desarrollar la capacidad empática hacia los pacientes.

- Desarrollar un conocimiento más profundo de cómo los seres humanos comunican sus emociones.

- Estimular la reflexión sobre las repercusiones de la actividad médica.

- Presentar la idea del paciente como un ser humano enfermo. 
opinión sobre los médicos y el resto de profesionales sanitarios. Con este objetivo consideramos útiles La escafandra y la mariposa (1997) de J ean Dominique Bauby, Con una sola pierna (1984) de Oliver Sacks, Diagnóstico cáncer (2000) de Miriam Suárez y Monte Sinaí (1995) de J osé Luis Sanpedro.

Los aspectos sociológicos de la enfermedad. La sociedad está formada por seres humanos y es indudable que la enfermedad, como afección personal, conlleva con frecuencia repercusiones en ambas direcciones. Por un lado, la afección de los pacientes influye en la conducta de las sociedades en que viven, pero el rechazo o la aceptación de éstas también modula la vivencia personal de la enfermedad. Para ilustrar tales problemas, escogemos La peste (1947) de Albert Camus, La enfermedad como metáfora (1979) de Susan Sontag, Veo una voz (1989) deOliver Sacks y P rinci pes de Maine (1985) de J ohn I rving.

La medicina como profesión: la relación médico-enfermo. Las dificultades del ejer cicio de la medicina, las diferencias entre la medicina hospitalaria y extrahospitalaria, así como los conflictos entre médicos y pacientes, se plantean con meridiana daridad en numerosas dbras, de las se recomiendan Memòries d'un cirurgià (2001) de Moisés Broggi, La casa deDios (1978) de Samuel Shem, La enfermedad de Sachs (1998) de Martín Winckler y Cuerpos y al mas (1935) de Maxence van der M eersch.

Los límites de la investigación médica. Dada la extensa actividad de investigación de los hospitales uni versitarios, es importante que los estudiantes reflexionen sobre su significado y cómo debe existir un compromiso entre el respeto a los enfermos y $\mathrm{d}$ progreso de la medicina. Asimismo, también deben conocer las tentaciones de fr aude que pueden aparecer en los investigadores. Empleamos para el lo Frankenstein (1831) de Mary Shelley, Muerte súbita (2000) de Michael Palmer, Dr. J eckyll y Mr. Hyde (1886) de Robert Louis Stevenson y, de nuevo, Cuerpos y al mas (1935) de Maxence van der Meersch.

Los profesores pueden esti rar y contraer estecurso tanto como deseen. De hecho, algunos de sus temas puede constituir un aurso por sí mismo. Las sugerencias de organización del curso tampoco deben seguirse a rajatabla: ed interés de los alumnos, la disposición del profesor y el tiempo disponible para la docencia le dar án la forma más adecuada en cada caso.

\section{Y UNAS CO NSIDERACIO NES F INAL ES}

La propuesta presentada en los párrafos anteriores es sólo una de las muchas existentes, pues cada profesor debe adaptar el curso a las necesidades de sus estudiantes. Se sugiere a los interesados la consulta de otros modelos como e propuesto por Downie y $\mathrm{cds}^{20}$. par a las facultades de medicina escocesas. En el campo de los recursos literarios, las posibilidades son múltiples y deben escogerse en función de los objetivos que se desee alcanzar. Pueden emplearse libros de relatos de los propios pacientes, dbras de médicos en clave autobiográfica o de pura ficción y, por supuesto, obras literarias, digamos puras, quetienen o no el problema médico como argumento central. On-Li neDatabase of Literature, Arts \& Medicine de la New York University School of Medicine (http//:endeavor.med.nyu.edu/lit-med) contiene un gran número de referencias comentadas que se ađualizan periódicamente. En esta base de datos pueden encontrarse numerosas sugerencias para ilustrar prácticamente cualquier tema de interés médico. Sin embargo, su contenido sebasa eminentemente (aunqueno de forma exdusiva) en referendias anglosajonas, muchas de ellas si n traducir al español o de difícil adquisición, dada la manía de los muchos editores de descatalogar las obras de su fondo editorial con rapidez enfermiza. La base de datos citada incluye escritores en lengua española como J orge Luis Borges (Los inmortales), Miguel de Cervantes (EI licenciadoVidriera), Gabrie García Márquez (EI amor en los tiempos de cólera), Carlos Fuentes (Aura), Ana María Matute (Primera memoria) o Mario Vargas Llosa (La guerra del fin de mundo). Además, incluye un buen número de películas de inter és en la docencia de la medicina.

Finalmente, existen dos obras que recomiendo a todos aquellos que desœn acercarse un poco más al mundo de las relaciones entre literatura y medicina desde e punto de vista docente La primera es Teaching, literature and medicine, en especial los capítulos de Hawkins y M cE ntyre ${ }^{6}$ y Charon ${ }^{21}$. La segunda es el ya citado Narrative based medicine ${ }^{14}$ sobre todo las contribuciones de Squier ${ }^{19}$ y Rachman ${ }^{22}$. Con su lectura, el lector tendrá opiniones más razonadas que la mía de porquéla literatura puede ayudar a los estudiantes de medicina a ser mejores médicos.

\section{CONCLUSIÓN}

La literatura constituye un reau rso docente notabilísimo para enseñar algunos aspectos de su futura profesión a los estudi antes de medi cina, que son si stemáticamente ignorados en los curricula tradicionales de muchas facul tades. La i mplantación de un curso sobre literatura y medicina puede ayudar a 
que los estudiantes se doten de un bagaje de conocimientos y actitudes queles ayudarán a ejer cer mejor su profesión. A ello contribuirán sin duda la consideración de aspectos muy importantes del proceso de enfer mar y de sus repercusiones psicológicas y sociológicas en los seres humanos.

\section{AGRADECIMIENTOS}

A Amparo J ordá por sus sugerencias sobre algunos de los textos que se incluyen como ejemplos y por compartir conmigo el placer por la lectura. A Ann Hunsadker Hawkins y a Philip Collins por su cálida acogida en Hershey.

\section{REFERENCIAS}

1. J ones AH. Literature and medicine: García Márquez' Love in the Time of Cholera. Lancet 1997; 350:1169-1172.

2. Rabuzzi KA (ed.) Toward a new discipline. Lit Med 1982; 1:1-118.

3. McLellan MF, J ones $A H$. Why literature and medicine? Lancet 1996; 348:109-111.

4. Strauss MB (ed) Familiar medical quotations. Little Brown and Co: Boston, 1968; 458 [cita extraída de la carta a A.S. Suvorin, 11 de septiembre de 1888].

5. Navarro F. Viaje al corazón de uno mismo. ¿Por qué demonios escriben los médicos? Discurso de ingreso en la Asociación Española de Médicos Escritores y Artistas (Asemeya). Madrid, 1999.

6. Hawkins AH, McEntyre MC. Introduction: Teaching literature and medicine: a retrospective and a rationale. En Hawkins $\mathrm{AH}, \mathrm{McE}$ ntyre MC (eds.) Teaching literature and medicine. The Modern Language Association: New York, 2000; 1-28.

7. MCManus IC. Humanity and the medical humanities. Lancet 1995; 346:1143-1145.
8. Yourcenar M. Memorias deAdriano. Edhasa: Barcelona, 1983.

9. Braunwald E. Edema. En Wilson JD, Braunwald E, Issel bacher KJ , Petersdorf RG, Martín J B, Fauci AS, Root RK (eds.) Harrison Principios de medicina interna. Vol. 1. 12a ed. Madrid: Interamericana, 1991; 275.

10. ReisineT, Pasternak G. Analgésicos opioides y sus antagonistas. En Hardman J G, Limbird LE, Molinoff PB, Ruddon RW, Gilman AG (eds.) Goodman \& Gilman Las bases farmacológicas de la terapéutica. Vol. 1. 9a ed. México: Interamericana, 1996; 575.

11. Beauvoir S. Una muerte muy dulce. Edhasa: Barcel ona, 1977.

12. Winckler M. La enfermedad de Sachs. Akal: Barcelona, 1999.

13. Allende I. Retrato en sepia. Plaza y J anés: Barcelona, 2000.

14. Greenhalgh T, Hurwitz B (eds.). Narrative based medicine. Londres: BMJ books, 1998.

15. Skelton J R, Thomas CP, Macleod J AA. Teching literature and medicine to medical students, part I: the beginning. Lancet 2000; 356:1920-1922.

16. Skelton J R, Thomas CP, Madeod J AA. Teaching literature and medicine to medical students, part II: why literature and medicine? Lancet 2000; 356: 2001-2003.

17. Hurwitz B. Narrative and the practice of medicine. Lancet 2000; 356:2086-2089.

18. Varios autores. Literature and ageing. Lancet 1999; 354 (Supl III):1-40.

19. Squier HA. Teaching humanities in the undergraduate medical curriculum. En Greenhalgh T, Hurwitz B (eds.). Narrative based medicine. Londres: BMJ books, 1998; 128-139.

20. Downie RS, Hendry RA, Manaughton RJ , Smith BH. Humanizing medicine: a special module. Med Educ 1997; 31:276280.

21. Charon R. Literary concepts for medical readers: frame, time, plot, desire. En Hawkins AH, McEntyre MC (eds.) Teaching literature and medicine. The Modern Language Association: New York, 2000; 29-41.

22. Rachman S. Literature and medicine. En Greenhalgh T, Hurwitz B (eds.). Narrative based medicine Londres: BMJ books, 1998; 123-128. 